\title{
Analysis of Heat Transfer During Quenching of a Gear Blank
}

Vivek Sahai

Salvador M. Aceves

This paper was prepared for submittal to the American Society of Mechanical Engineers International Mechanical Engineering Congress and Exposition Nashville, TN

November 14-19, 1999

March 1999

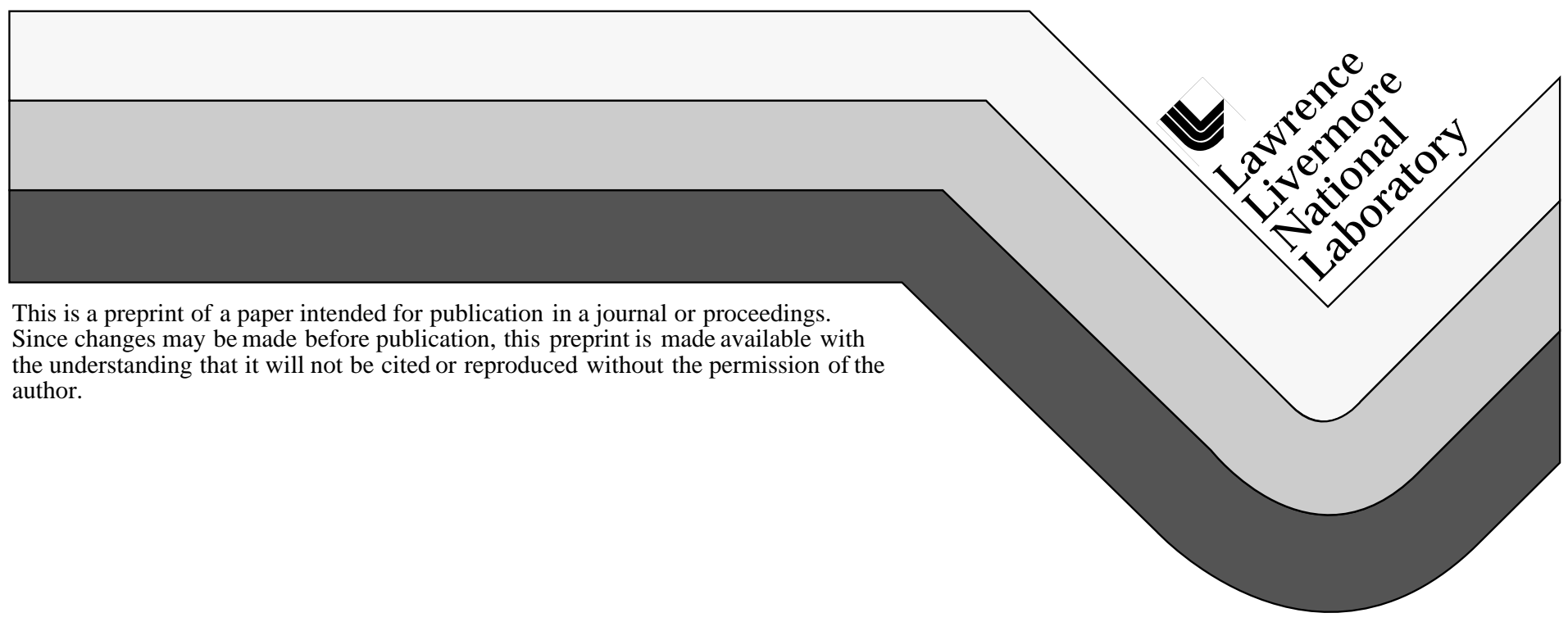




\section{DISCLAIMER}

This document was prepared as an account of work sponsored by an agency of the United States Government. Neither the United States Government nor the University of California nor any of their employees, makes any warranty, express or implied, or assumes any legal liability or responsibility for the accuracy, completeness, or usefulness of any information, apparatus, product, or process

disclosed, or represents that its use would not infringe privately owned rights. Reference herein to any specific commercial product, process, or service by trade name, trademark, manufacturer, or otherwise, does not necessarily constitute or imply its endorsement, recommendation, or favoring by the United States Government or the University of California. The views and opinions of authors expressed herein do not necessarily state or reflect those of the United States Government or the University of California, and shall not be used for advertising or product endorsement purposes. 


\title{
ANALYSIS OF HEAT TRANSFER DURING QUENCHING OF A GEAR BLANK
}

\author{
Vivek Sahai and Salvador M. Aceves \\ Lawrence Livermore National Laboratory \\ P.O. Box 808, L-140 \\ Livermore, CA 94551 \\ sahai1@1lnl.gov
}

\begin{abstract}
This paper presents experimental and numerical results for the quench of a gear blank in agitated and stagnant oil. Heat transfer within the gear blank is analyzed with a whole domain-optimizer technique inverse solution method, to calculate the time history at every point in the gear blank. The development of this procedure represents the first stage in an overall analysis of the quench process that will later include material phase transformations and deformation.
\end{abstract}

The paper presents ten variations in setting up the inverse problem, to analyze which combination of independent variables and decision variables results in the best match between experimental and numerical results. The results indicate that dividing the boundary of the gear blank into four zones and assigning a fixed heat transfer coefficient or heat flux to each zone yields an average RMS error (average difference between experimental and numerical results) of the order of $40 \mathrm{~K}$. This error can be reduced by either increasing the number of zones, by reducing the number of thermocouples being matched, or by allowing the heat transfer or heat flux to vary within the zones. Of these 
possibilities, variation of heat transfer within the zones gives the best improvement in the quality of the match for the amount of extra effort required to run the problem.

\section{INTRODUCTION}

Quenching of metallic parts is an important manufacturing technique to control hardness and toughness of these parts. Quenching often occurs under transient two-phase flow conditions that makes analysis of heat transfer and fluid mechanics difficult or impossible (Nelson and Pasamehmetoglu, 1984). In addition to this, quenching involves material phase transitions, stresses and distortions. All of these have to be analyzed simultaneously to obtain an accurate description of the process (Arola et al., 1993).

This work is part of a multi-institution, interdisciplinary effort to develop a simulation tool for doing a complete analysis of the quench problem (Dowling et al., 1997). As a first step in the overall quench analysis, this paper is focused on the thermal part of the problem. Future work will link the solution of the thermal problem with the material phase characteristics and stresses.

The difficulty associated with the multiphase heat transfer conditions under quenching makes it necessary to analyze the process as an inverse problem based on experimental thermocouple data (Archambault et al., 1997). Inverse heat transfer analysis implies in this case the calculation of boundary heat fluxes from measured temperatures within a 
part. Inverse heat transfer problems are known to be ill-posed, which means that the results of the problem are very sensitive to small variations in the data input (Beck et al., 1985; Kurpisz and Nowak, 1995).

Many techniques have been developed for the analysis of inverse heat transfer problems. A very common procedure is Beck's method (Beck et al., 1985), which has been applied to the quench of nickel cylinders (Park et al., 1989). New methods are currently being developed, which present advantages for particular types of problems (Martin and Dulikravich, 1998).

A preliminary phase of this project (Lin et al., 1997) consisted of an evaluation of available techniques for solution of inverse heat transfer problems. The methods evaluated included Burgraff’s (Burgraff, 1964); Beck’s (Beck et al., 1985); Trujillo's (Trujillo and Busby, 1989); and a whole domain-optimizer approach. The whole domain-optimizer approach defines heat transfer coefficients (or heat fluxes) as a number of functions of position and time (or temperature), and then uses an optimizer to find the best match between the calculated and the experimental data. Lin et al. (1997) concluded that the present availability of fast, inexpensive computers makes the whole domain-optimizer approach the easiest to implement and execute, and the least sensitive to noisy data (noise occurs as a result of the formation and detachment of vapor bubbles, Park et al., 1991). This is especially true when the methods are applied to complex geometries and nonlinear conditions (temperature-dependent properties). The whole domain-optimizer 
approach has been applied to a quench problem in a recent publication (Singh and Palle, 1997).

\section{PROBLEM DESCRIPTION}

This paper presents an analysis of heat transfer during quenching of a metallic ring (gear blank). The axisymmetric cross section of the gear blank is shown in Figure 1. The gear blank is $23 \mathrm{~mm}$ high, has an inner radius of $18 \mathrm{~mm}$, and an outer radius of $28 \mathrm{~mm}$. The analysis uses the whole domain-optimizer technique, and considers different formulations of the problem to identify the best methodology. The objective is to determine the surface heat fluxes from cooling curves measured during the quenching of a gear blank in stagnant and agitated oil. As previously discussed, no phase changes or distortions in the gear blank are considered at this stage of the analysis.

The experimental data used in this study were obtained from the placement of thermocouples (K-type) at various locations on the surface of the steel gear blank as shown in Figure 1. The figure shows the thermocouple locations with dots. These thermocouples were brazed in holes through the gear. Thermocouples on the inner diameter, outer diameter, top and bottom surfaces are identified with the letters I, O, T and B. Ten thermocouples were installed in each surface. Redundant thermocouples were installed on all surfaces to check for symmetry and to improve the odds of obtaining a full set of data from a single experiment, during which some thermocouples may fail. 
Redundant thermocouples were installed at the same axial and radial position on the gear blank, at either $90^{\circ}$ or $180^{\circ}$ from each other in the azimuthal direction. Some thermocouples did fail during the experiment. Failed thermocouples are not shown in Figure 1. The upper and the inner surfaces had the maximum number of failed thermocouples (4), and no usable data were obtained at the top of the inner hub or at the center of the inner surface.

The thermocouple data were taken in four separate experiments, to limit the number of thermocouple wires that may interfere with the quenchant flow and heat transfer inside the gear blank. In each experiment, data were taken for one of the four surfaces of the gear blank (inner, outer, top and bottom). Each experiment consisted of taking data while the part was heated in the furnace (at approximately $1130 \mathrm{~K}$ ), moved out into the air above the quenchant tank, and then lowered into the quenchant. Figure 2 shows experimental data for four thermocouples during these three stages of the process. The quenchant used in the experiment is oil. Data from the thermocouple were sampled at a high rate (330 readings/second) to capture the large temperature drops that occur during the first few seconds of quenching. Data were obtained for both stagnant and agitated oil. The oil was agitated by using a jet generator, which circulates oil from the bottom to the top of the quenchant tank.

\section{ANALYSIS}


Raw data obtained from the experiments have to be modified before using it for the solution of the inverse problem. There are two reasons for this. One is noise in the data and the other is the need to align the data to the point in which the gear blanks were immersed in the oil.

Noise in the data is due to bubble formation and detachment. The experimental data show noise similar to that observed by Park et al. (1990). To smooth out the noise, a linear least squares fit was applied to the data. A fitting routine fits a line for every twenty points of data, and replaces the twenty points with the center point of this line. Smoothing the data by this technique helps retain the general shape of the cooling curves, especially the sharp change in slope of the temperature data at the start of the quench. Work using other techniques (such as Fourier fitting) tends to hide the detail at the start of the quench.

The smooth data still have to be aligned. This is necessary because the data were obtained from four separate experiments, each for a different side of the gear blank. The inverse solution method requires simultaneous data for the whole gear blank, as could have been obtained by installing thermocouples on the four sides of the gear blank during the same experiment. This was not desirable, because so many wires may interfere with the flow, boiling and heat transfer during the quench.

Data were aligned by determining the time for which the gear blank was introduced into the oil. This time is set as $\mathrm{t}=0$ in the analysis, and it is assumed that the thermocouple 
readings in the four sides of the gear blank apply simultaneously starting at this time. It is easy to determine the time of immersion into the oil quenchant, because oil immersion introduces a sharp change in the slope of the temperature data.

Alignment introduces some errors. Ideally, the four experiments required to measure the temperatures in the four sides of the gear blank would be carried out under identical conditions, from the heating inside the furnace to the transport to the oil to the immersion in oil (see Figure 2). However, this is not possible. The time required for extracting the parts from the furnace and immersing them in oil was not constant, but varied between 42 to 48 seconds for the four experiments. Considering that the gear blank cools down in air at an approximate rate of $1.8 \mathrm{~K} / \mathrm{s}$, the difference in immersion time introduces a maximum error of the order of $10 \mathrm{~K}$. This error is small compared to the temperature change during quenching, and no attempt was made to compensate for it. A sensitivity analysis was done in which the temperatures measured in one of the sides of the gear blank were increased by $10 \mathrm{~K}$ for the whole quench process. The relative error in heat transfer coefficients due to this change was $5 \%$. Considering that the $10 \mathrm{~K}$ temperature difference is reduced rapidly due to heat transfer during quenching, it is expected that the effect of the difference in immersion time is much less than the $5 \%$ calculated in this analysis.

Another effect not considered by the alignment procedure is the fact that different thermocouples reach the oil surface at different times. The bottom of the gear blank reaches the oil first, and the top reaches the oil last. An analysis of the experimental 
results yields an average speed of immersion of $160 \mathrm{~mm} / \mathrm{s}$. This gives an overall time of $0.14 \mathrm{~s}$ for the part to enter the quenchant. A run was made by starting the analysis at the time when the top of the part is immersed. This run resulted in an average change of heat transfer coefficient of $2.8 \%$. However, this value is not a true indication of the error, because the time interval being analyzed is different (it is shifted by $0.14 \mathrm{~s}$ ). The real error caused by neglecting the immersion time is difficult to calculate, but is expected to be less than the $2.8 \%$.

The smooth and aligned data are then reduced to a sequence of 101 values for each thermocouple, starting from $\mathrm{t}=0$ and continuing to $\mathrm{t}=10 \mathrm{~s}$, with a constant time step of $0.1 \mathrm{~s}$ between points. Only these $10 \mathrm{~s}$ of the overall process are analyzed (Figure 2), because this period is the most important for determining the properties of the gear blank, and also because this period is the most difficult to analyze. These $10 \mathrm{~s}$ cover the boiling phase of the quench process. Good agreement was obtained between redundant thermocouples, and the results change little when any of the redundant thermocouples are used for the analysis.

An initial temperature field is necessary to solve the heat transfer problem for the gear blank. In this analysis, the initial temperature field was obtained from a steady-state calculation that uses the thermocouple measurements at $\mathrm{t}=0$ (immersion time) as a boundary condition. 
The grid used for the numerical analysis is shown in Figure 1. This grid has 190 elements and 222 nodes, and was selected as a compromise between accuracy and running time. Grid sensitivity of the results was tested by using a finer grid with 1737 nodes. The results of a typical run changed by less than $1 \%$.

The whole domain-optimizer technique is implemented by using a finite element heat transfer code (TOPAZ2D; Shapiro and Edwards, 1990), and linking it to an optimizer (Global Local Optimizer, GLO; Murphy and Baker, 1995). TOPAZ2D solves the heat conduction equation (written in terms of enthalpy, $\mathrm{H}$ ):

$\rho\left(\frac{\partial \mathrm{H}}{\partial \mathrm{t}}\right)=\nabla \bullet(\mathrm{k} \nabla \mathrm{T})$

where $\rho$ is the density and $\mathrm{k}$ is the thermal conductivity. In this analysis, thermal conductivity, specific heat, and density of the austenite phase of stainless steel are used (Sjostrum, 1982). The boundary conditions that TOPAZ2D allows at the surfaces of the gear blank are either a specification of heat flux(q) or the heat transfer coefficient(h) as a function of time(t) or temperature(T). Additionally, TOPAZ2D has the ability to allow either the heat flux or the heat transfer coefficient to vary along the surface with the specification of curve multipliers along the surfaces. GLO has a configuration file that allows easy linking of the two codes (Sahai et al., 1998). The configuration file assigns values to the decision variables, calls TOPAZ2D, reads the results, calculates the figure of merit, and assigns new values to the decision variables, depending on the result obtained 
for the figure of merit. The process is repeated until the figure of merit converges to the minimum within a desired tolerance.

The optimization problem was solved for multiple cases, to determine the conditions that result in a more accurate prediction of the cooling curves at all locations during the quenching process. The figure of merit for the optimization is the sum of the squares of the differences in temperature between the experiment and the results of TOPAZ2D during the $10 \mathrm{~s}$ of the quench process being analyzed, for a set of selected thermocouple locations. Different cases are run with different thermocouples and different numbers of thermocouples selected for comparison with the numerical data.

Multiple cases are also considered for the decision variables. The decision variables are either heat transfer coefficients or heat fluxes. Heat transfer coefficients or fluxes can be expressed as a function of time or as a function of surface temperature. The analysis considers the surface of the gear blank to be divided in zones. Heat transfer coefficients or fluxes can be assumed uniform within a zone, or they may be allowed to vary as a function of position within a zone. The number of zones is also varied. Similar cases with agitated and stagnant oil are considered. The combinations used are far from being exhaustive, but they do cover a wide range of conditions and are expected to offer a good guidance in selecting a methodology for future stages of this project. 


\section{RESULTS}

Table 1 shows a list of all the cases being considered. Ten cases are presented for both agitated and stagnant oil, for a total of 20 runs. Most of the cases presented have 4 zones. For the runs with 4 zones, Figure 1 shows the location of the zones along the surface of the gear blank. Most of the cases presented consider all 17 thermocouples in the analysis. In these cases, the experimental data obtained for the 17 thermocouples are compared with the numerical predictions at these locations to obtain the figure of merit (the sum of the squares of the differences for the 101 values of time considered during the quench). Six cases use the heat transfer coefficient as decision variable, and 4 use heat flux as decision variable. It is important to identify the conditions under which each one of these is a better decision variable.

The independent variable for the boundary conditions is either temperature or time. The decision variables (heat transfer coefficients or heat fluxes) are expressed as a function of either temperature or time within each zone. The decision variables are determined for 6 different values of time or temperature (6 decision variables per zone), and a linear interpolation is used between these 6 values. For the cases with time as independent variable, the values of time are: $0 \mathrm{~s}, 1 \mathrm{~s}, 2 \mathrm{~s}, 4 \mathrm{~s}, 7 \mathrm{~s}$, and $10 \mathrm{~s}$. More values are used in the early stages of the process, where the temperature is changing the fastest. When temperature is the independent variable, the decision variables are determined for $1100 \mathrm{~K}$, $1000 \mathrm{~K}, 900 \mathrm{~K}, 800 \mathrm{~K}, 700 \mathrm{~K}$ and $400 \mathrm{~K}$. 
In most of the cases, heat transfer coefficients or fluxes are assumed to remain uniform within a zone, being only a function of either temperature or time. In cases 9 and 10 , additional decision variables (location parameters) are introduced to allow heat flux to vary as a function of position within a zone. A number of locations (13 in case 9 and 22 in case 10) are selected on the surface of the gear blank, and a location parameter is assigned to every location. Heat flux is then specified as a function of location by doing a linear interpolation between the values of the location parameters. This method results in a heat flux that is both a function of time or temperature and a function of location within a zone.

The number of decision variables is listed in Table 1. This is an important parameter that determines the length of the optimization runs. The number of decision variables is calculated as 6 times the number of zones, plus the number of location parameters.

Table 1 also shows the figure of merit and the average RMS error per measurement, both for agitated and for stagnant oil. The results of Table 1 indicate that the average RMS error is of the order of $40 \mathrm{~K}$ in most of the cases that consider 4 zones. Using more zones, matching less thermocouples, or allowing the decision variables to change within the zones results in an improved match and in reduced figures of merit. Table 1 also shows that there is no clear difference in RMS error between the agitated and the stagnant oil 
cases. Some cases show better agreement for the agitated case and some cases show better agreement for the stagnant case.

The columns for Cases 1 and 2 show that specifying $h$ as a function of time, $h(t)$, yields a slightly better result than specifying $h$ as a function of temperature, $h(T)$. On the other hand, Cases 3 and 4 indicate that $\mathrm{q}(\mathrm{T})$ yields a better match than $\mathrm{q}(\mathrm{t})$.

Cases 5 and 6 indicate that increasing the number of zones results in an improved match between the experimental and the numerical results. However, adding zones results in more decision variables, and a longer run time. The additional zones in these cases were placed on the outer and inner surfaces in Case 5 and also on the bottom surface in Case 6 .

Cases 7 and 8 show that reducing the number of thermocouples matched in the analysis substantially reduces the average error. Case 8 has average errors that are much smaller than the errors obtained in any of the other cases. However, this is obtained at the cost of ignoring the rest of the experimental data, and the prediction for the experimental data for locations not considered in the analysis may not be very good.

Cases 9 and 10 show that allowing the heat flux to vary within the zones as a function of position results in a much-reduced figure of merit and average error. This improvement in the agreement is obtained at the cost of increasing the number of decision variables, as in Cases 5 and 6. However, a significant improvement is obtained in the quality of the match 
for a relatively low number of additional decision variables. Comparing Cases 9 and 10 to Cases 5 and 6, it can be concluded that allowing the decision variables to vary within a zone is a more efficient method to improve the quality of the match when compared to adding more zones.

Figures 3 through 9 illustrate some of the most important results. Figure 3 shows a comparison between experimental and numerical results for Cases 1 and 2, for agitated oil (Case 1 uses $h(t)$ and Case 2 uses $q(t))$. The comparison is only presented for 4 of the 17 thermocouples being matched (O4, I8, T5, and B6). Experimental results are shown as solid lines, and numerical results are shown as dotted lines. The Figure shows that most experimental results overpredict the temperature, with the exception of thermocouple O4, for which the analysis underpredicts the temperature. It must be considered that Figure 3 shows data from only 4 out of the 17 thermocouples being used in the analysis, and better agreement is obtained for other thermocouples in the set.

Figure 4 shows a comparison similar to Figure 3, for the case of stagnant oil. The figure shows a comparison between experimental and numerical results for Cases 1 and 2 . The comparison is presented for the same 4 thermocouples as in Figure 3 (O4, I8, T5, and B6). Figure 4 shows a better agreement between experimental and numerical results than Figure 3, which is consistent with Table 1, that indicates a lower figure of merit for stagnant oil in Cases 1 and 2. 
Figure 5 shows heat transfer coefficients for the four zones as a function of time for case 1 ( $\mathrm{h}$ as a function of $\mathrm{t}$ ) for stagnant and agitated oil. The results for agitated oil are shown with solid lines, and the results for stagnant oil with dotted lines. The figure shows the typical shape of the quench lines, with a maximum heat transfer coefficient in the early stages of the process, which indicates the transition from film boiling to nucleate boiling (Nelson and Pasamahmetoglu, 1984). As expected, the cases with agitated oil have a higher heat transfer coefficient, especially in the later stages of the process, where the intensity of nucleate boiling decreases, and heat transfer is more sensitive to fluid flow.

Figure 6 shows heat flux as a function of time for the four zones, for case 2 ( $q$ as a function of t). The results for agitated oil are shown with solid lines, and the results for stagnant oil with dotted lines. Heat flux lines have the same typical shape as shown for the heat transfer coefficient in Figure 5. Once more, a higher heat flux is obtained for agitated oil as compared with stagnant oil.

Figure 7 shows a temperature comparison between experimental and numerical results for Case 8 (h as a function of $\mathrm{t}$, and only 4 thermocouples matched), for stagnant oil. The four thermocouples matched are O4, I8, T5 and B6. The figure shows the experimental results with solid lines, and the numerical results with dotted lines. The figure also shows a comparison between experimental and numerical results for thermocouple I1, which is not being matched in the optimization (it is not being used in the definition of the figure of merit). The figure shows that there is an excellent agreement between the experimental and 
the numerical results for the four thermocouples being matched. As shown in Table 1, Case 8 with stagnant oil has the lowest figure of merit and RMS error $(2.87 \mathrm{~K})$ of all cases considered. This is due to the small number of thermocouples being matched and the large number of decision variables (24). However, as previously discussed, matching only four thermocouples ignores the rest of the experimental data, and big differences may exist between experimental and numerical data in other locations. This is illustrated in Figure 7 with thermocouple I1, which is not among the four thermocouples being matched. Figure 7 indicates that the experimental and numerical results for I1 are very different, indicating that using too few thermocouples may result in significant errors at some locations, even though some measurements are fitted with great accuracy.

Figure 8 shows a comparison between experimental and numerical temperatures for case 10 (q as a function of temperature, for variable $q$ within the zones), for quenching in agitated oil, for thermocouples O4, I8, T5 and B6. The figure shows the experimental results with solid lines, and the numerical results with dotted lines. The figure shows a very good match between experimental and numerical results, which is much improved compared to the agreement shown in Figures 3 and 4 for Cases 1 and 2. According to these results, allowing the heat flux to vary within the zones as a function of temperature results in a much-improved match without requiring an excessively high number of decision variables. 
Figure 9 shows heat flux as a function of temperature for Case 10, for all thermocouple locations in the outer gear blank surface. The curves in Figure 9 show a maximum flux at intermediate conditions along the quench, in agreement with the results presented in Figure 6. Maximum heat flux was obtained at a temperature of $800 \mathrm{~K}$.

\section{CONCLUSIONS}

This paper presents experimental and numerical results for the problem of quenching a steel gear blank. The problem uses a whole domain-optimizer technique, which is coupled to a direct solver of the heat conduction equation to set up and solve the inverse problem. The paper considers ten variations in setting up the inverse problem, to study which combination of figure of merit, independent variable, and decision variable results in the best match between experimental and numerical results. The main results obtained in the analysis are:

1. Setting up the problem by dividing the surface of the gear blank in 4 zones, assigning a fixed heat transfer coefficient or heat flux to each zone and considering 17 sets of experimental thermocouple data yields an average RMS error (average difference between experimental and numerical results) of the order of $40 \mathrm{~K}$.

2. Increasing the number of zones improves the match between experimental and numerical results. However, this also increases the number of decision variables and the running time. 
3. A smaller number of thermocouples can be matched better than the full set of 17 thermocouples. A case that considers only 4 thermocouples can be matched to within an average RMS error of only $2.8 \mathrm{~K}$. However, reducing the number of thermocouples may result in significant error in locations far from the thermocouples in the reduced set.

4. The quality of the match can also be improved by allowing the heat transfer coefficient or heat flux to vary within a zone as a function of position. As in the case of increasing the number of zones, this method requires the introduction of additional decision variables. However, variation of heat flux or heat transfer coefficient within the zones yields the best improvement in the quality of the match with a small amount of additional computational effort.

This work was performed under the auspices of the U.S. Department of Energy by Lawrence Livermore National Laboratory under contract No. W-7405-Eng-48.

\section{REFERENCES}

Archambault, P., Denis, S., and Azim, A., 1997, "Inverse Resolution of the Heat Transfer Equation with Internal Heat Source: Application to the Quenching of Steels with Phase Transformations," Journal of Materials Engineering and Performance, Vol. 6(2), pp. 240246.

Arola, R., Martikainen, H., and Virta, J., 1993, “Computer-Aided Simulation of Heat Treatment," Technical Research Center of Finland, VTT Publications 131, Finland. 
Beck, J.V., Blackwell, B., and St. Clair, C.R., 1985, "Inverse Heat Conduction, Ill-Posed Problems," John Wiley and Sons, New York, NY.

Burggraff, O.R., 1964, "An Exact Solution of the Inverse Problem in Heat Conduction Theory and Applications," ASME Journal of Heat Transfer, Vol. 86 part C, pp. 373-382.

Dowling, W., Pattok, T., Ferguson, B.L., Shick, D., Gu, Y.H., and Howes, M., 1997, "Development of a Carburising and Quenching Simulation Tool: Program Overview," Heat Treatment of Metals, Vol. 1, pp. 1-6.

Kurpisz, K., and Nowak, A.J., 1995, “Inverse Thermal Problems,” Computational Mechanics Publications, Southampton, UK.

Lin, M.Y., Murphy, M., Shapiro, A.B., and Stein, W., 1997, "Numerical Methods for Inverse Heat Transfer Analysis," Lawrence Livermore National Laboratory Internal Report, Livermore, CA.

Martin, T.J., and Dulikravich, G.S., 1998, "Inverse Determination of Steady Heat Convection Coefficient Distributions," Journal of Heat Transfer, Vol. 120, pp. 328-334.

Murphy, M. J., and Baker, E. L., 1995, “GLO: Global Local Optimizer,” Lawrence Livermore National Laboratory Unclassified Code 960007, Livermore, CA.

Nelson and Pasamehmetoglu, 1984, "Quenching Phenomena," in Post-Dryout Heat Transfer, Edited by Hewitt, Delhaye and Zuber, CRC Press, Boca Raton, FL, 425 pp.

Park, J.E., Childs, K.W., and Ludtka, G.M., 1989, “Quenching Heat Flux Calculated Using Information From Deeply Buried Thermocouples," in ASME HTD-Vol. 112, Heat Transfer Measurements, Analysis and Flow Visualization, Edited by R.K. Shah, pp. 3138.

Park, J.E., Chu, W., and Ludtka, G.M., 1990, “Smoothing Strategies for Surface Temperatures Measured During Vigorous Transient Boiling," in ASME HTD-Vol. 129, General Papers: Phase Change and Convective Heat Transfer, Edited by K. Vafai, M.A. Ebadian, T. Diller, M.K. Jensen, T.W. Simon, A.G. Lavine and W. Aung, pp. 91-99.

Park, J.E., Childs, K.W., and Ludtka, G.M., 1991, "Correcton of Errors in Intrinsic Thermocouple Signals Recorded During Quenching," Heat Transfer - Minneapolis 1991, AIChE Symposium Series, Vol. 87, No. 283, pp. 309-318.

Sahai, V., Aceves, S., and Stein, W., 1998, "Explanation of How to Run the Global Local Optimization Code (GLO) to Find Surface Heat Flux", Lawrence Livermore National Laboratory Internal Report, Livermore, CA. 
Shapiro, A.B., and Edwards, A.L., 1990, “TOPAZ2D Heat Transfer Code Users Manual and Thermal Property Data Base," Lawrence Livermore National Laboratory Report UCRL-ID-104558, Livermore, CA.

Singh, D.P.K., and Palle, N., 1997, "Determination of Heat Transfer Coefficients for Quenching Simulation: An Optimization-Based Approach,” Ford Research Technical Report No. SR-97-112, Project No. AJ445.

Sjostrom, S., 1982, “The Calculation of Quench Stresses in Steel,” Ph.D. Thesis, Linkoping University, Linkoping, Sweden.

Trujillo, D.M., and Busby, H.R., 1989, “Optimal Regularization of the Inverse Heat Conduction Problem,” Journal of Thermophysics, Vol. 3, pp. 423-427. 
Table 1. Description of Cases Studied Using the GLO Optimizer and TOPAZ2D

\begin{tabular}{|c|c|c|c|c|c|c|c|c|c|c|}
\hline case & 1 & 2 & 3 & 4 & 5 & 6 & 7 & 8 & 9 & 10 \\
\hline zones & 4 & 4 & 4 & 4 & 7 & 10 & 4 & 4 & 4 & 4 \\
\hline thermocouples & 17 & 17 & 17 & 17 & 17 & 17 & 14 & 4 & 17 & 17 \\
\hline decision variables & $\mathrm{h}$ & $\mathrm{q}$ & $\mathrm{h}$ & $\mathrm{q}$ & $\mathrm{h}$ & $\mathrm{h}$ & $\mathrm{h}$ & $\mathrm{h}$ & $\mathrm{q}$ & $\mathrm{q}$ \\
\hline $\begin{array}{c}\text { independent variable } \\
\text { time }\end{array}$ & time & $\begin{array}{c}\text { temper- } \\
\text { ature }\end{array}$ & $\begin{array}{c}\text { temper- } \\
\text { ature }\end{array}$ & time & time & time & time & $\begin{array}{c}\text { time } \\
\text { temper- } \\
\text { ature }\end{array}$ \\
\hline $\begin{array}{c}\text { decision variables per } \\
\text { zone }\end{array}$ & 6 & 6 & 6 & 6 & 6 & 6 & 6 & 6 & 6 & 6 \\
\hline $\begin{array}{c}\text { uniform h or q within } \\
\text { zone? }\end{array}$ & uniform & uniform & uniform & uniform & uniform & uniform & uniform & uniform & variable & variable \\
\hline location parameters & 0 & 0 & 0 & 0 & 0 & 0 & 0 & 0 & 13 & 22 \\
\hline $\begin{array}{c}\text { total decision } \\
\text { variables }\end{array}$ & 24 & 24 & 24 & 24 & 42 & 60 & 24 & 24 & 37 & 46 \\
\hline $\begin{array}{c}\text { figure of merit, } \\
\text { agitated oil }\end{array}$ & $3.03 \times 10^{6}$ & $4.11 \times 10^{6}$ & $3.49 \times 10^{6}$ & $2.57 \times 10^{6}$ & $2.81 \times 10^{6}$ & $1.26 \times 10^{6}$ & $2.26 \times 10^{6}$ & $1.57 \times 10^{4}$ & $8.89 \times 10^{5}$ & $5.01 \times 10^{5}$ \\
\hline $\begin{array}{c}\text { figure of merit, } \\
\text { stagnant oil }\end{array}$ & $2.93 \times 10^{6}$ & $3.68 \times 10^{6}$ & $3.78 \times 10^{6}$ & $2.64 \times 10^{6}$ & $2.68 \times 10^{6}$ & $1.55 \times 10^{6}$ & $2.54 \times 10^{6}$ & $3.34 \times 10^{3}$ & $8.86 \times 10^{5}$ & $3.98 \times 10^{5}$ \\
\hline $\begin{array}{c}\text { average RMS error, } \\
\text { agitated oil }\end{array}$ & 42.0 & 48.9 & 45.1 & 38.7 & 40.5 & 27.1 & 40.0 & 6.23 & 22.8 & 17.1 \\
\hline $\begin{array}{c}\text { average RMS error, } \\
\text { stagnant oil }\end{array}$ & 41.3 & 46.3 & 46.9 & 39.2 & 39.5 & 30.0 & 42.4 & 2.87 & 22.7 & 15.2 \\
\hline
\end{tabular}




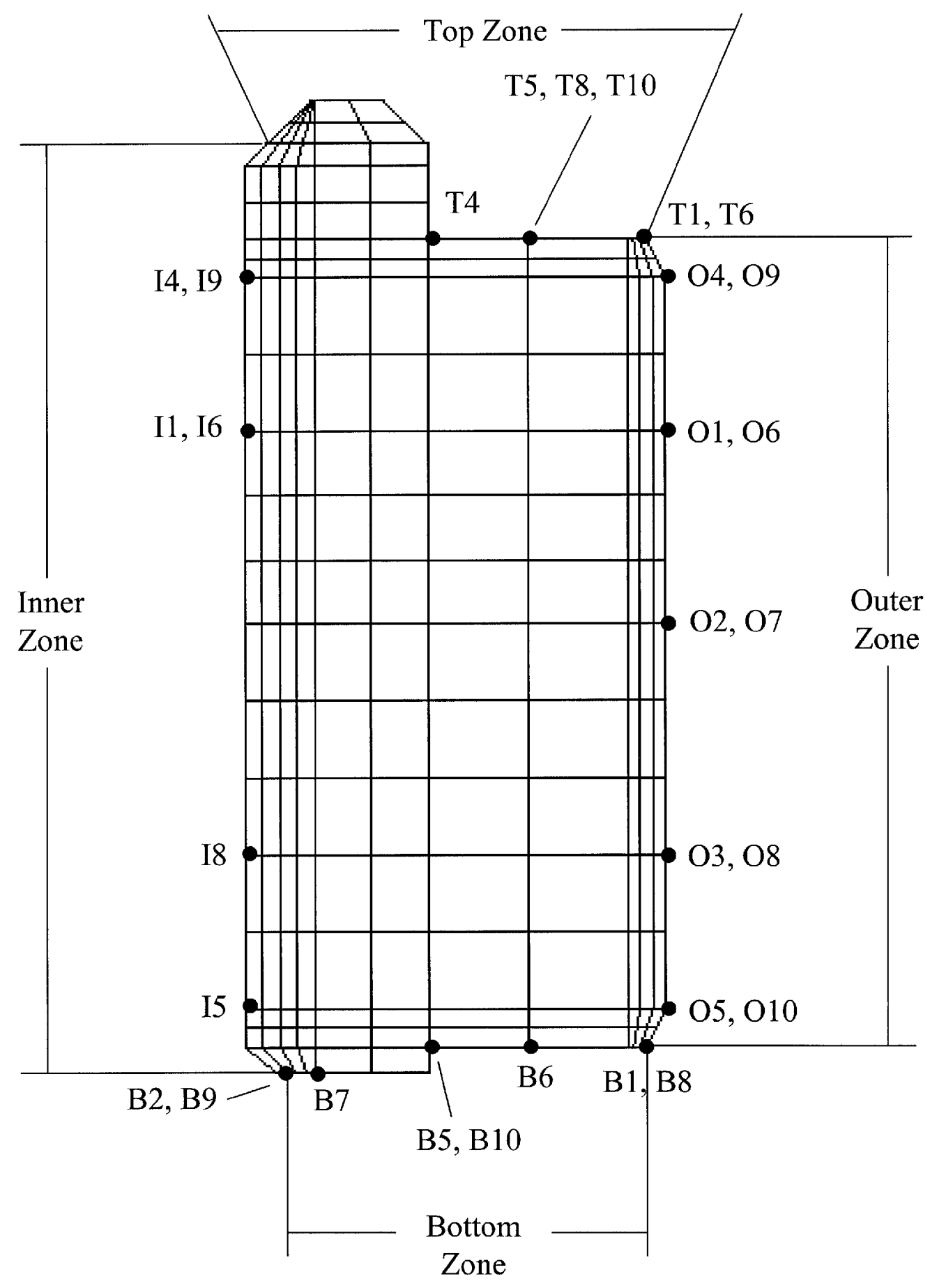

Figure 1. Cross-sectional view of gear blank, including the mesh used in optimization study, thermocouple locations (indicated by dots) and zone definitions for the 4-zone runs. 


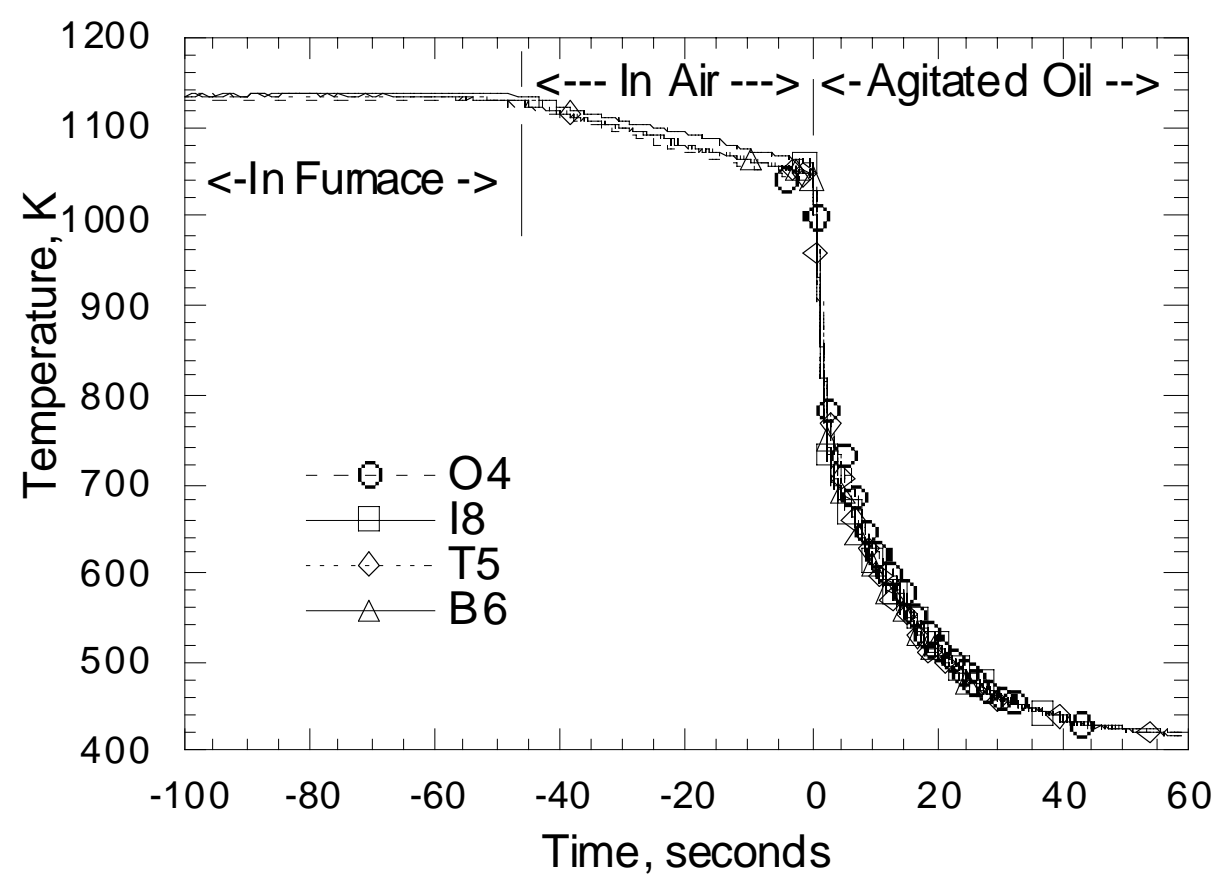

Figure 2. Experimental data showing temperature of four thermocouples during furnace heating, air cooling and quench in agitated oil. 


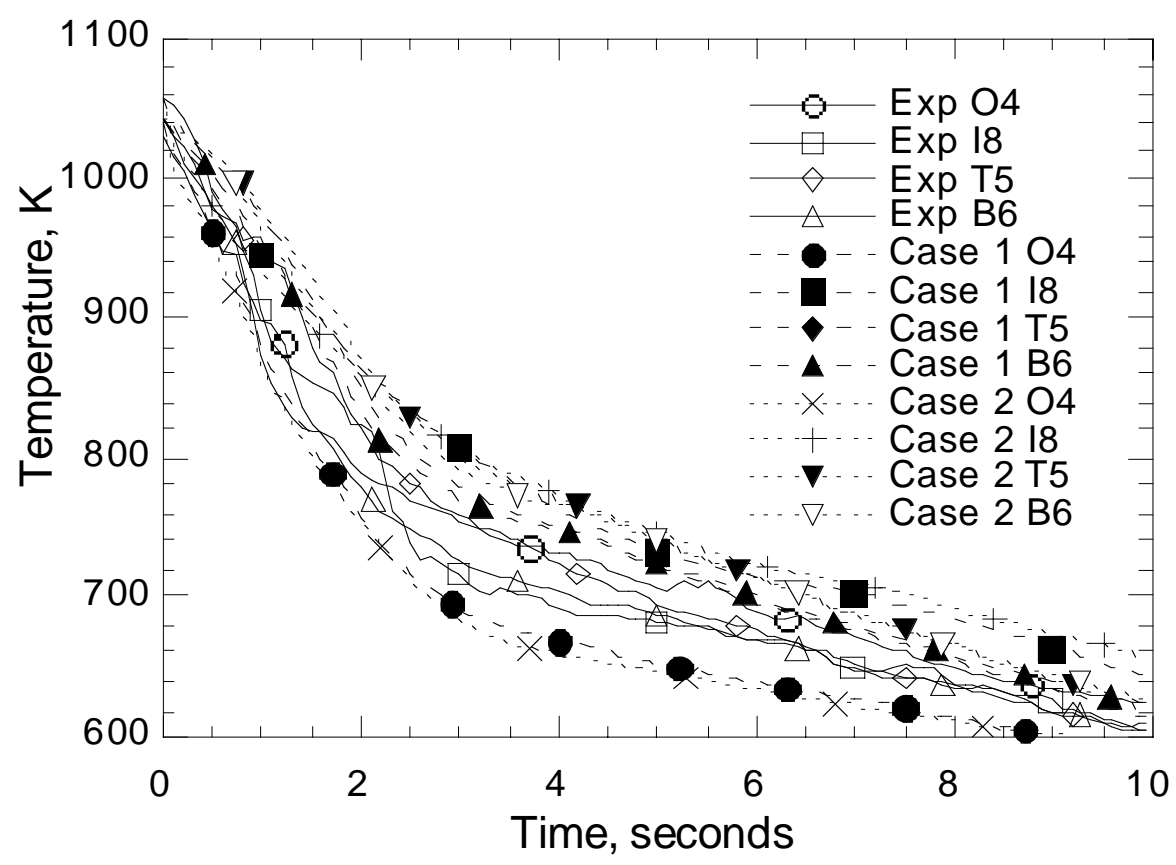

Figure 3. Comparison between experimental and numerical results for Cases 1 and 2, for agitated oil (Case 1 uses $h(t)$ and Case 2 uses $q(t))$. The comparison is only presented for 4 out of the 17 thermocouples being matched (O4, I8, T5, and B6). Experimental results are shown as solid lines, and numerical results are shown as dotted lines. 


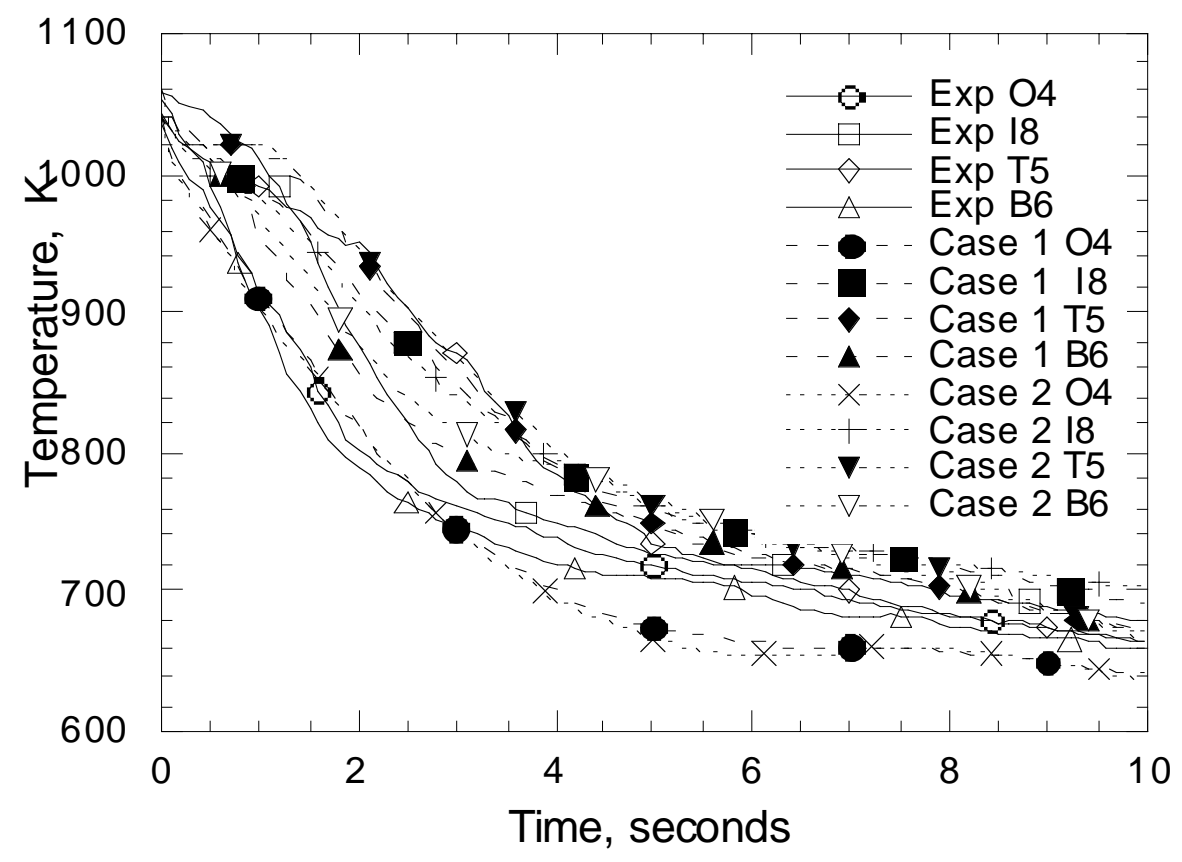

Figure 4. Comparison between experimental and numerical results for Cases 1 and 2, for stagnant oil (Case 1 uses $h(t)$ and Case 2 uses $q(t))$. The comparison is only presented for 4 out of the 17 thermocouples being matched (O4, I8, T5, and B6). Experimental results are shown as solid lines, and numerical results are shown as dotted lines. 


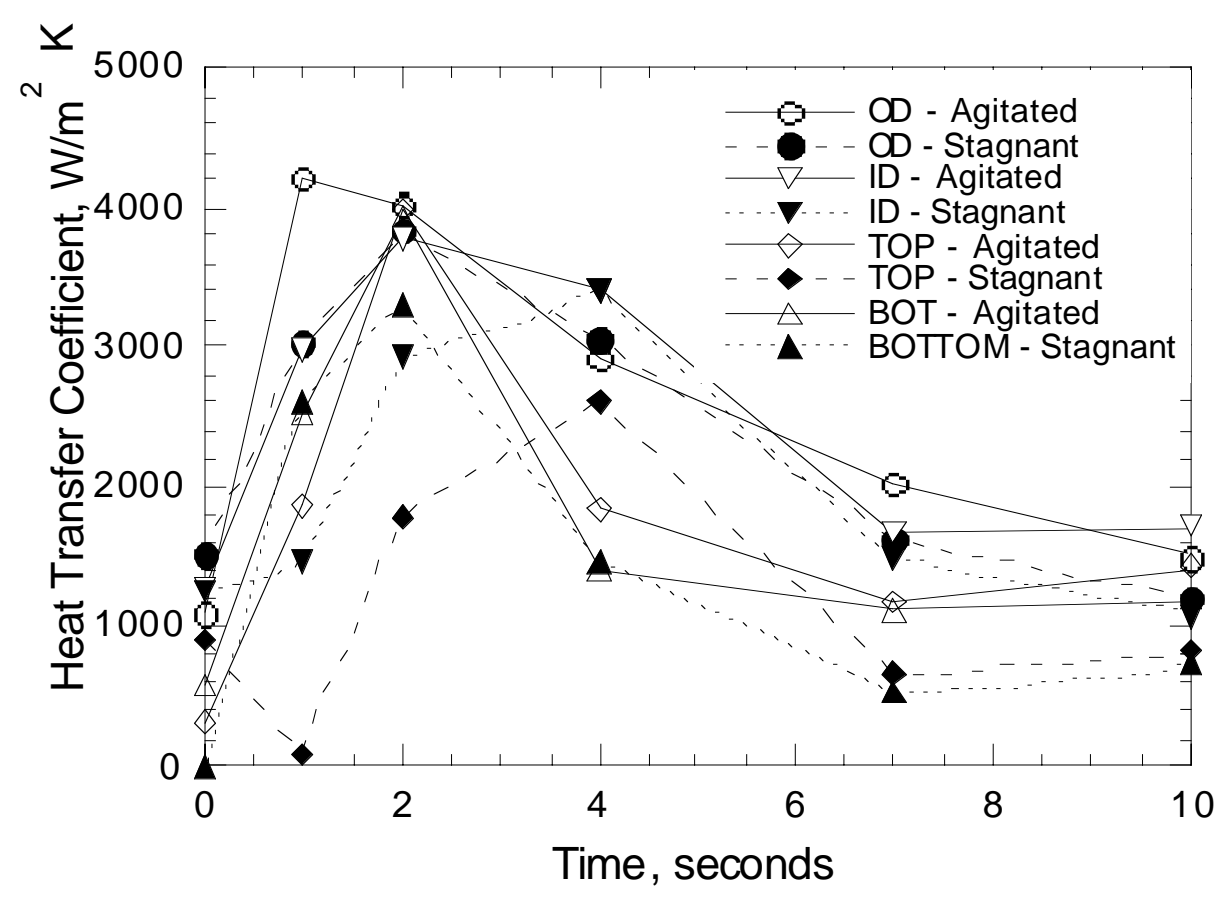

Figure 5. Heat transfer coefficients for the four zones (OD- Outer Zone, ID- Inner Zone, Top- Top Zone, and Bottom- Bottom Zone as shown in Figure 1) as a function of time for case 1 ( $h$ as a function of $t$ ) for stagnant and agitated oil. The results for agitated oil are shown with solid lines, and the results for stagnant oil with dotted lines. 


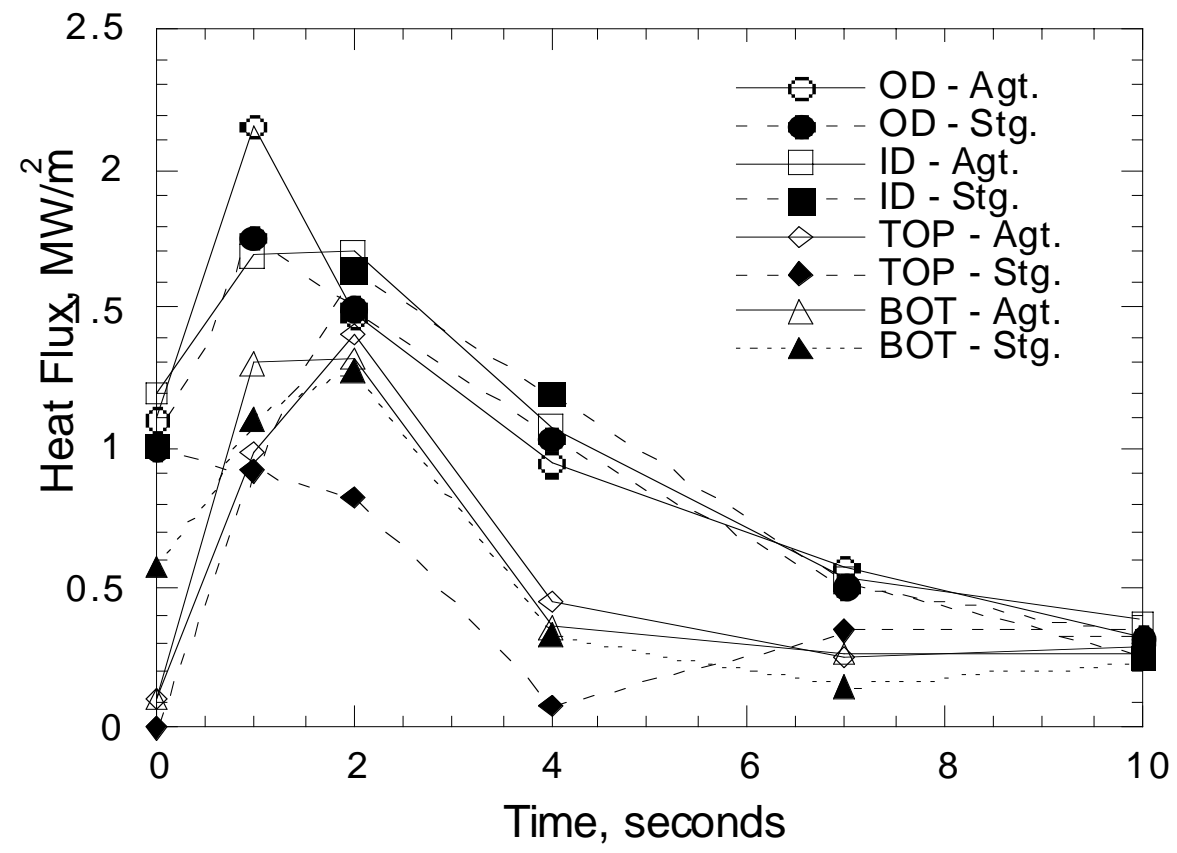

Figure 6. Heat flux as a function of time for the four zones (OD, ID, top and bottom), for case 2 ( $q$ as a function of $t$ ). The results for agitated oil are shown with solid lines, and the results for stagnant oil with dotted lines. 


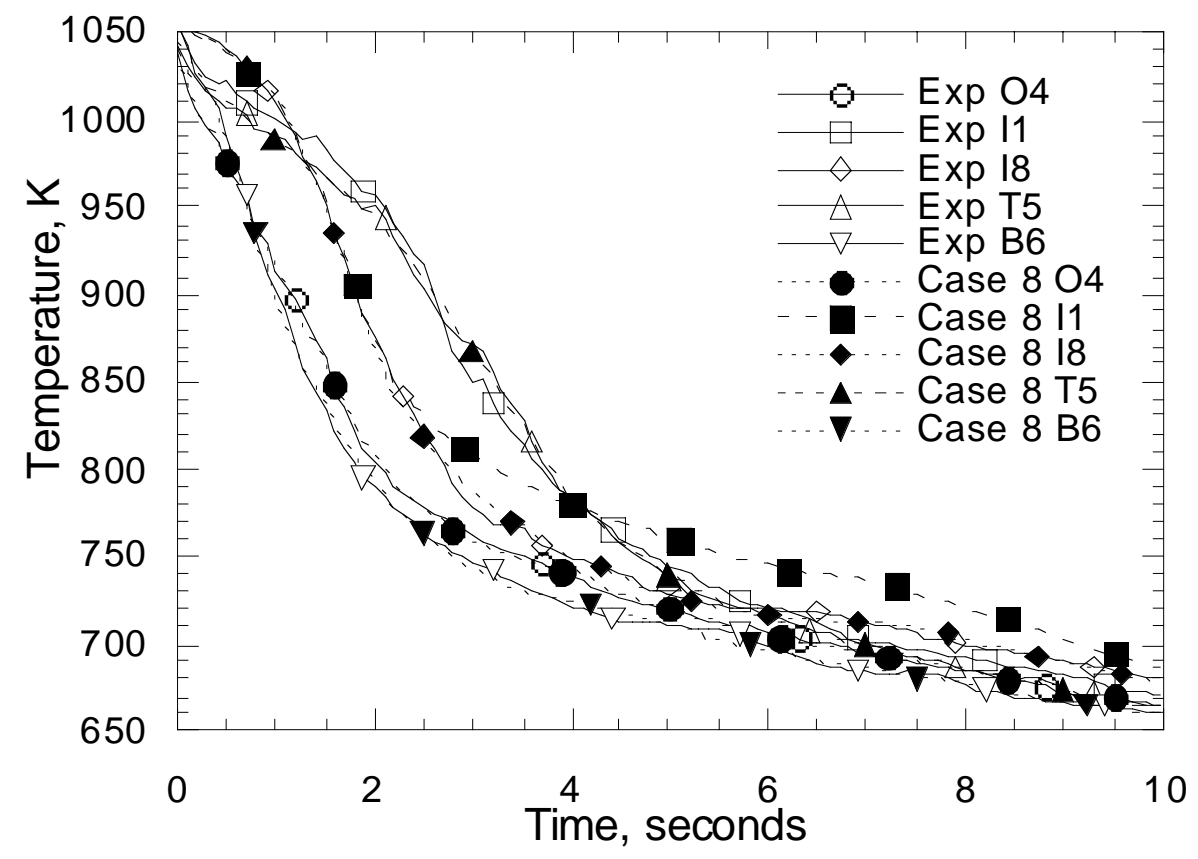

Figure 7. Temperature comparison between experimental and numerical results for Case 8 (h as a function of $\mathrm{t}$, and only 4 thermocouples matched), for stagnant oil, for thermocouples O4, I8, T5, B6 and I1. The figure shows the experimental results with solid lines, and the numerical results with dotted lines. 


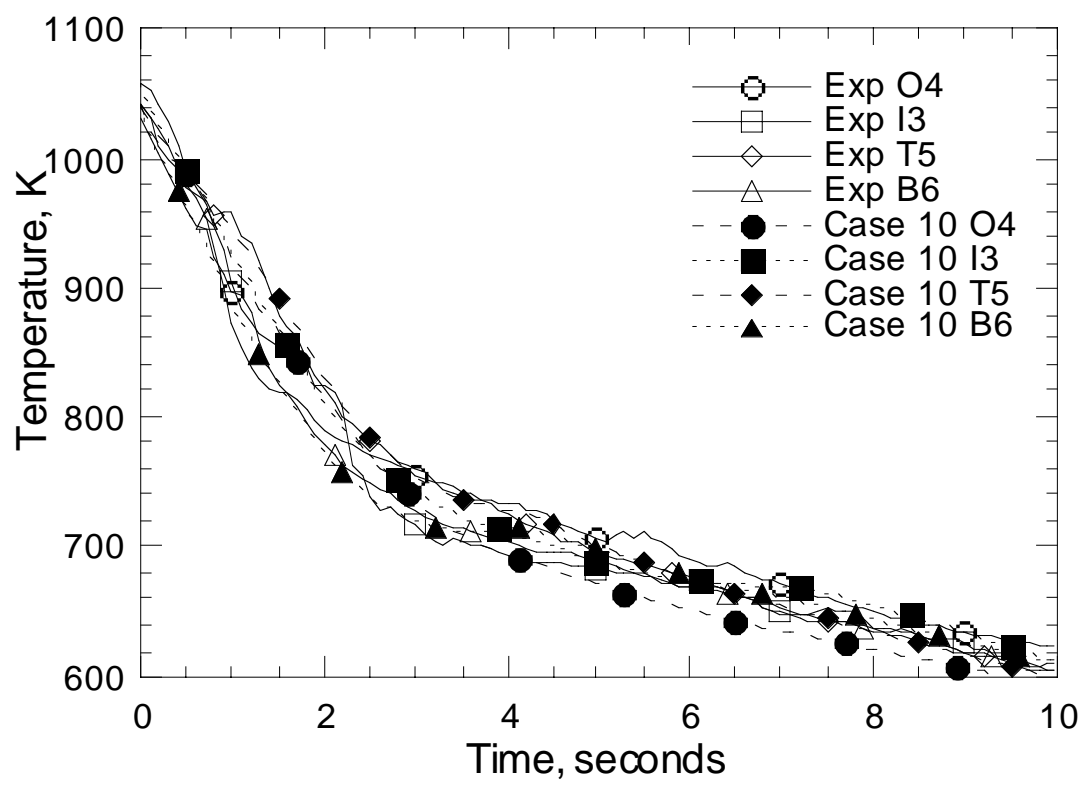

Figure 8. Comparison between experimental and numerical temperatures for case 10 ( $\mathrm{q}$ as a function of temperature, for variable $q$ within the zones), for quenching in agitated oil, for thermocouples $\mathrm{O} 4, \mathrm{I} 8, \mathrm{~T} 5$ and B6. The figure shows the experimental results with solid lines, and the numerical results with dotted lines. 


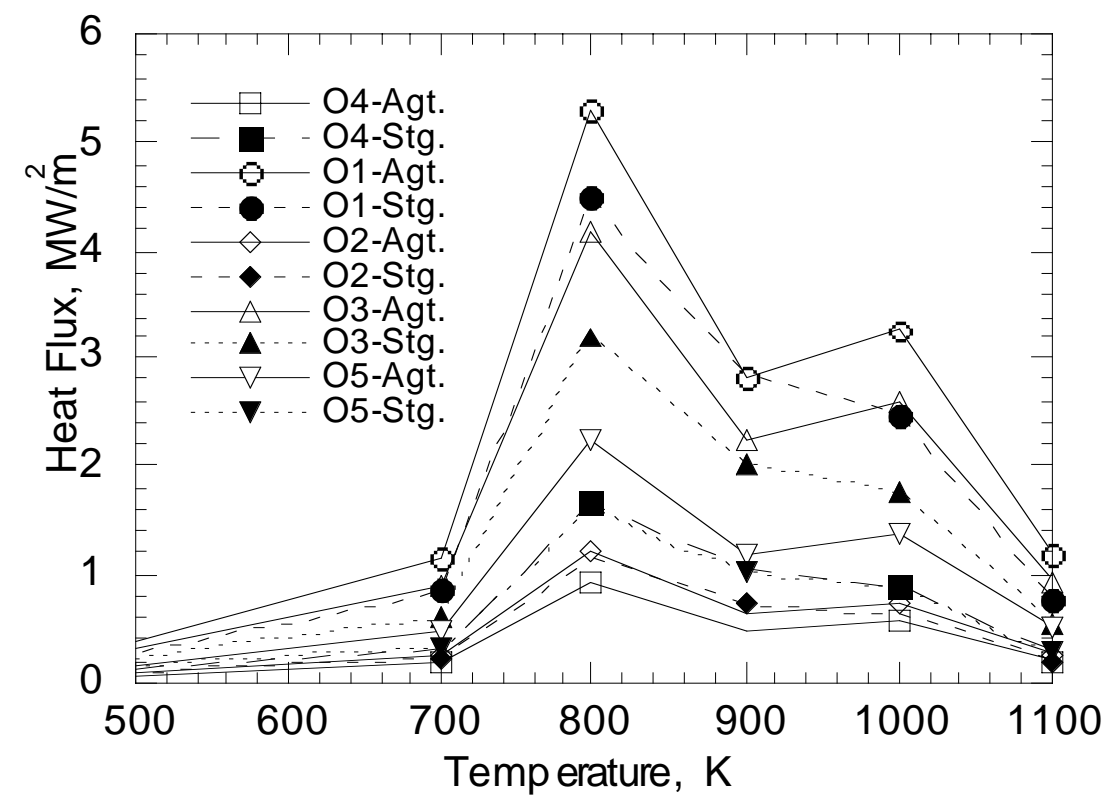

Figure 9. Results from Case 10 for both agitated and stagnant oil showing flux as a function of temperature along the outer diameter surface at the thermocouple locations indicated. 